\title{
Structure and Thermodynamics of Drug-RNA Aptamer Interactions
}

J.B. Da Costa and T. Dieckmann 1

l University of Waterloo, Dept. of Chemistry, 200 University Ave West, Waterloo, ON, Canada, E-mail: tdieckma@ uwaterloo.ca; Fax: +1-5197460435; Tel: +1-519-8884567

\begin{abstract}
This mini-review will provide an overview on the recent studies of structure and thermodynamics of RNA aptamers that target drug molecules. These aptamers are studied to provide insight into RNA drug interactions. This interaction is important due to the many roles RNA plays in cell biology.
\end{abstract}

Key Words: Ribonucleic acid, aptamer, thermodynamics, isothermal titration calorimetry, RNA structure. 


\section{RNA IN BIOLOGY AND MEDICINE}

Ribonucleic acids (RNA) participate in many cellular processes including protein translation, signalling, and regulation $[1,2]$. The first function of RNA identified was the transfer of information from deoxyribonucleic acid (DNA) to proteins. The RNA was termed messenger RNA or mRNA [3]. In this model DNA is responsible for information storage and proteins are responsible for catalytic function [4, 5], with RNA simply serving as a carbon copy of DNA. The discovery that RNA was capable of catalyzing RNA cleavage changed the perception of RNA's function [6, 7]. RNA sequences that are capable of catalytic activity are called ribozymes. This discovery led to the proposal of the RNA world hypothesis which suggests that early life went through a stage where RNA was responsible for information storage and catalytic function [8].

\section{RNA in translation}

The discovery of mRNA was followed by the identification of ribosomal RNA (rRNA) [9] and transfer RNA (tRNA) [10]. rRNA interacts with specific proteins to form the ribosome [11] which is responsible for translation of mRNA code to protein sequence. It achieves this through interactions with tRNA and mRNA [12]. tRNA assists the transcription of codons by acting as a translator [13]. The ribosome brings together mRNA, based on complementary interaction of mRNA codon and tRNA anti-codon [14]. This is followed by the peptidyl transferase reaction which is catalyzed by the ribosome. [15]. The discovery that the RNA component of the ribosome is responsible for the catalytic activity further emphasizes the central role that RNA plays in biochemistry and supports the idea of an RNA world at the origin of life. This function of RNA showed that large proteins required RNA to be synthesized and were possible after RNA developed this ability [16].

\section{$R N A$ in regulation}

In the past 20 years more classes of RNA with diverse functions have been identified; these include small interfering RNA (siRNA) [17], micro RNA (miRNA) [1], small nucleolar RNA (snoRNA) [18], piwi interacting RNA (piRNA) [19], long non-coding RNA (lncRNA) [20] and riboswitches [21]. In addition to these, RNA has also been observed recently to function as an extracellular signalling molecule [22]. These RNAs functions in conjunction with protein molecules to achieve gene regulation.
siRNA and miRNA are short sequences of RNA that form double stranded strands with target RNAs via Watson Crick base pairing. These double stranded RNAs are then targeted by cellular degradation mechanisms [23]. The difference between siRNA and miRNA lies in the role they play in cellular biochemistry. siRNA are largely regarded as defense against exogenous RNA while miRNA is responsible for regulation of endogenous genes [24]. snoRNAs identify RNA for modification and guide proteins to the modification sites. These modifications, including methylation and pseudouridylation, are important for proper folding in rRNA and tRNA [25]. piRNA are a testis specific class of RNA. They participate in gene silencing similar to miRNA and siRNA, and have been found to target sequences that are prone to relocating themselves within the genome also known as transposons [26]. With the exception of mRNA the above mentioned RNA are non-coding RNA (ncRNA), meaning that they have function other than providing the code for translation. Long ncRNA are ncRNA that are longer than 200 nucleotides. IncRNA can be processed to make siRNA or miRNA but are also functional as regulators in long form [20]. Riboswitches are sequences of RNA that bind to a specific small molecule target. The binding event causes a change in structure that regulates transcription of a neighbouring gene [27].

\section{RNA therapeutics}

The diverse and central roles that RNA plays in cells make it an appealing target for molecular therapeutic and diagnostic applications. RNA can be a candidate for a potential drug molecule itself due to the variety of molecules it can interact with. Using systematic evolution of ligands by exponential enrichment (SELEX) [28, 29] it is possible to select for an RNA sequence that targets a specific molecule or cell type. RNA sequences with a high affinity for a specific target are referred to as aptamers [28]. Even though this term was initially only applied to RNAs that were selected in vitro, it has since been expanded to include naturally occurring aptamers. These natural aptamers include riboswitches which are not only able to bind to a specific target but also play a role in gene regulation [27].

Currently there are several aptamers in phase I and II clinical trials [30]. These include aptamers for treatment of coronary artery bypass [31], macular degeneration [32] and acute myeologenous leukemia [33]. Macugen is an aptamer based drug that targets vascular endothelial growth factor (VEGF) currently available for treatment of macular degeneration [34]. This aptamer is conjugated to a polyethylene glycol (PEG) to increase its lifetime in vivo. PEG increases 
the lifetime of biomolecules in vivo by changing the biomolecules hydrophobicity and electrostatic binding properties [35]. PEGylation turns the main disadvantages of RNA drugs, the low lifetime due to degradation, into an advantage by allowing tailoring of the lifetime of the drug based on size of PEG. It should be mentioned that therapeutics developed with siRNA [36] and ribozymes [37] have also shown some promise and several clinical trials are in progress. However, a detailed discussion of these systems is beyond the scope of this review.

Research into the nature of the interactions between target and drug molecule has helped to improve protein targeting molecules. For example, in the case of protein kinase inhibitors structural work revealed non catalytic sites that could be targeted [38]. Investigation into the structure of VEGF and aptamer binding has revealed the interaction with the VEGF heparin binding domain [39]. More recently, the same approach is being taken with RNA targeting small molecules by using aptamer models to understand nature of interactions between RNA and small molecules.

This review attempts to provide an overview of the structural and thermodynamic information currently available for RNA aptamer interactions with proteins, RNA and small molecules. These studies form a crucial foundation for applying medicinal chemistry approaches to novel targets involving RNA.

\section{LARGE BIOMOLECULE RNA APTAMER INTERACTIONS}

Much effort has been directed at developing aptamers that target the human immunodeficiency virus (HIV) by specifically targeting the HIV regulator of virion expression (Rev) peptide, trans-activation response element (TAR) HIV RNAs or the HIV trans activator of transcription (Tat) peptide [40 - 42].

\section{HIV Rev peptide}

The HIV Rev peptide binds to the envelope gene at the Rev response element site. It is responsible for transporting mRNA that encodes viral proteins to the cytoplasm [43-44]. The studies of the structures of HIV rev peptide in complex with RNA aptamers demonstrate how RNA can influence the structure of its ligand. Depending on the RNA sequence the peptide binds in either a $\alpha$-helical or elongated conformation $[42,46]$. This knowledge is important if the peptide RNA complex is to be targeted by inhibitors.

\section{HIV Tat}

The HIV Tat peptide binds to the TAR HIV RNA and is necessary for transcription initiation, a vital part of the viral life cycle [47]. The HIV Tat aptamer complex was initially studied by using the simplest analog of Tat, an argininamide molecule [41].

Argininamide was used as an analog of Tat since the peptide is arginine rich and an arginine residue was implicated in binding to the TAR region [48]. This structure revealed the aptamer was binding two argininamide molecules suggesting that it interacts with two arginine residues on the peptide [41]. Inhibition of binding of Tat to TAR was observed when Tat is captured by aptamer, demonstrating that the aptamer is binding either at or near the TAR binding site [49].

\section{TAR-HIV RNA}

The interaction of the aptamer selected against TARHIV RNA reveals a kissing complex where non canonical RNA-RNA interactions along with stacking interactions create a stable intermolecular structure (Figure 1) [50]. These types of complexes are important to the viral life cycle. For example, the HIV-1 genomic RNA dimerization initiation site (DIS) kissing complex formed by two DIS elements triggers viral RNA dimerization [51]. It has been shown that the hydrogen bonding network within the kissing complex along with intermolecular stacking interactions is responsible for molecular recognition [40]. 
A)

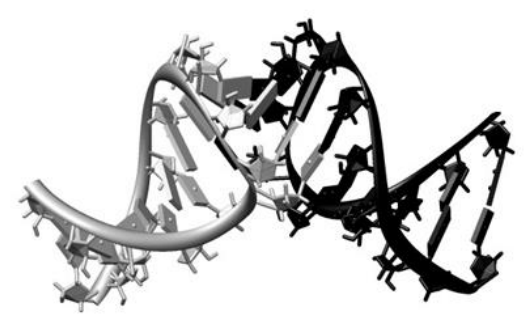

B)

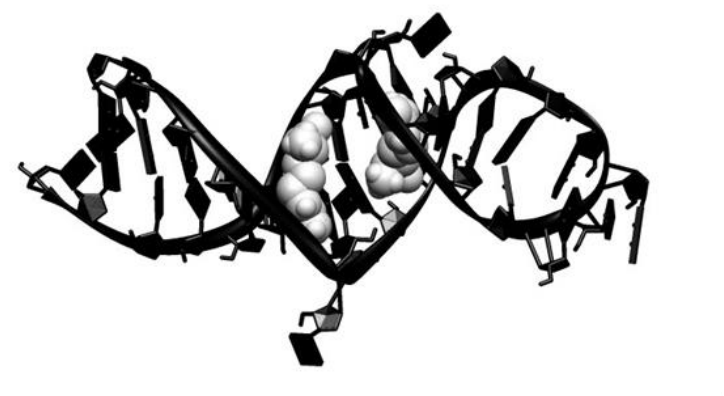

C)

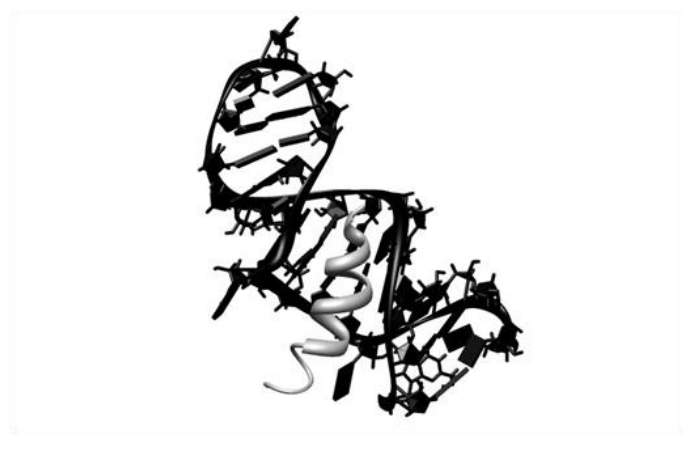

D)

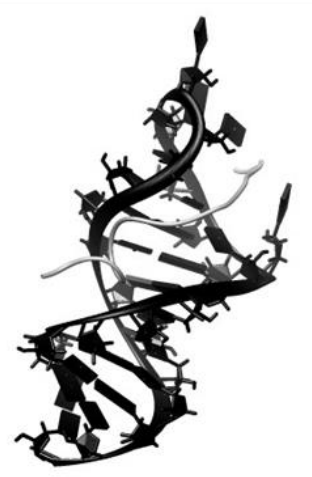

Figure 1.

HIV related RNA aptamers. Aptamers in black, Target molecules in grey. A) TAR - TAR aptamer complex, PDB ID 2RN1 [50], showing the "kissing" interaction. B) HIV Tat aptamer in complex with two argininamide molecules, PDB ID 1NBK [41], showing the RNA wrapped around the molecules. C) HIV Rev peptide aptamer complex, PDB ID 1ULL [46], showing the peptide in the groove of the RNA. D) HIV Rev peptide aptamer complex, PDB 484D [42], showing the extended peptide bound to aptamer. Figure was generated using UCSF Chimera [52].

\section{MS2 coat protein}

Another virus that has been targeted for aptamer development is bacteriophage MS2. This virus has been used as a model system to study RNA-protein interactions [53, 43]. The MS2 coat protein is responsible for recognition of a stem loop within the genome and binding to this loop is part of a process that initiates encapsidation [55]. Structural investigations of this aptamer and MS2 coat protein revealed that the aptamer binds to the protein in a similar manner to other stem loop RNA's. This binding interaction involves the phosphodiester backbone of the RNA. Phosphates of the backbone undergo subtle rearrangements that lead to different affinities when mutations were studied. The effect of rearrangement of the phosphate backbone changes the hydrogen bonding network, Horn et al. suggest that predicting these changes will lead to better $d e$ novo design of RNA binding ligands [56].

\section{RNA polymerase}

Viral RNA interactions are not the only RNA interactions of interest that have been addressed by aptamer development. Other targets include RNA polymerases and initiation factors. RNA polymerases, the enzymes responsible for transcription of DNA to RNA can be inhibited by binding of RNA molecules $[57,58]$. Structural work on the RNA aptamer bound to RNA polymerase II (Figure 2A) highlighted a possible mechanism for inhibition. The aptamer binding blocks the initiation center so template DNA cannot reach the catalytic center. B2 RNA is a ncRNA that supresses mRNA transcription by inhibiting RNA polymerase II in response to heat shock [59]. Competitive binding of B2 RNA and RNA polymerase II RNA aptamer to RNA polymerase II was investigated by Kettenberger et al. The absence of B2 RNA binding revealed by these 
experiments suggests that B2 RNA may bind in the same way as the aptamers [60]. The 6S RNA also binds to RNA polymerase II. Based on the RNA aptamer that binds in A-form within the RNA polymerase II cleft it was suggested that this maybe

A)

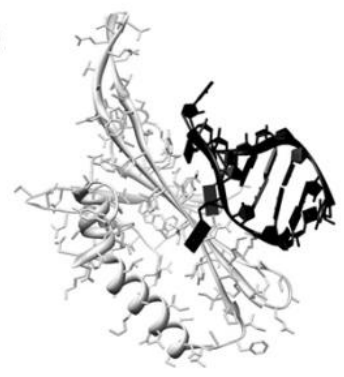

B)

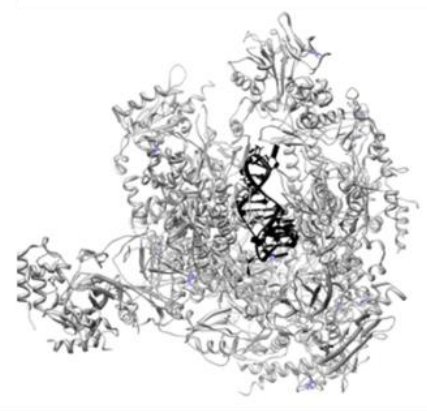

C)

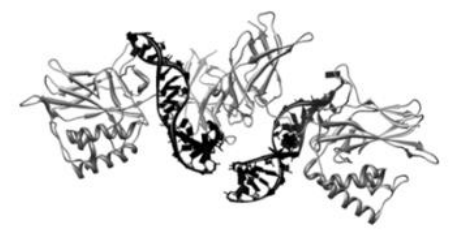

how 6S RNA binds [58]. This observation expands the understanding of how the RNA polymerase II cleft interacts with RNA, in addition to accommodating B-form DNA templates [60].

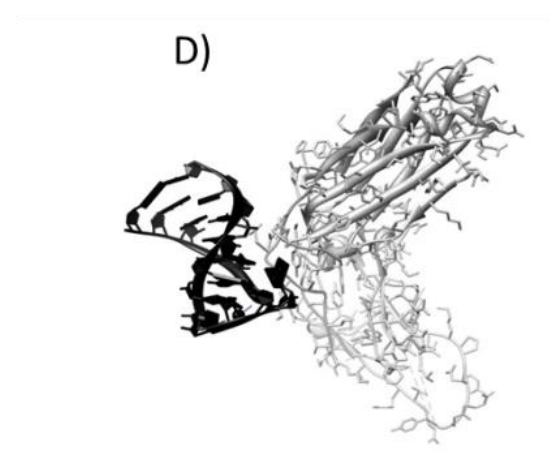

E)

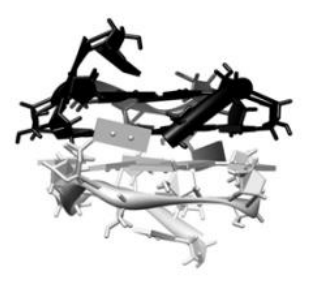

Figure 2. $\quad$ RNA aptamer (black) bound to protein targets (grey) A) MS2 coat protein, PDB ID 1U1Y [56], showing the loop interaction between protein and RNA. B) RNA polymerase II, PDB ID 2 B63 [60], showing the aptamers buried within the polymerase. C) NF-kb homodimer, PDB ID 1OOA [61], showing the RNA helix interacting with protein. D) Human IgG, PDB ID 3AGV [70], showing interaction between RNA and specific site on protein (Tyr 333). E) Prion protein aptamer, PDB ID 2RQJ [66], this structure lacks the target protein, however the quadruple structure shown here is key to the interaction with protein, in this case both black and grey represent RNA. Figure was generated using UCSF Chimera [52].

\section{Transcription and Initiation factors}

Transcription factors are proteins that bind to the DNA sequences regulating transcription. The NF- $\kappa b$ factor is involved in activating genes and has been the target of therapeutic inhibition of cancer cells [62]. In the case of the mammalian transcription factor NF- $\mathrm{kb}$ binding, the RNA aptamer mimics DNA structure (Figure 2B). The pre-bound structure of the RNA resembles B-form DNA. The RNA upon binding to NF- $\kappa b$ adapts to the presence of the protein [63]. Initiation factors are proteins that bind to the ribosome during translation. The mammalian initiation factor 4A binding interaction with its RNA aptamer were studied by obtaining structures of individual RNA aptamer loops and evaluating the interactions with the initiation factor. These studies suggest that binding involves the interaction of the aptamer's AUCGCA loop with the initiation factor [64]. Future structural work may reveal how these aptamers could interfere with the different factors and affect protein expression.

\section{Prion protein}

RNA aptamers have also been used to study protein targets whose primary function does not involve interaction with RNA, such as prion proteins and immunoglobulins. Prion proteins are infectious particles responsible for diseases like Creutzfeldt Jacob disease and spongiform encephalopathy [65]. The RNA aptamer for bovine prion utilizes the electrostatic interaction between its phosphate 
backbone and lysine clusters, along with stacking interactions between its GGGG quadruplex and a tryptophan residue to achieve binding [66]. Prion protein has been found to bind to amyloid- $\beta$ oligomers leading to synaptic dysfunction. This aptamer has been proposed for development as a therapeutic agent for Alzheimer's disease, since the prion protein plays a role in impairment of synaptic plasticity [67]. The prion aptamer has already been shown to reduce the formation of prion protein in infected cells, most likely by preventing prion protein from interacting with native proteins [68].

\section{Human immunoglobulin $G$}

Human immunoglobulin $\mathrm{G}(\mathrm{IgG})$ is a protein responsible for identifying pathogens [69]. The structure of human IgG bound to its aptamer reveals the interactions that make the RNA specific for this particular immunoglobulin. The interactions involve stacking of bases with Tyr373; unlike other protein RNA interactions the binding is not driven by the interaction of negatively charged phosphate and positively charged surface of protein [70]. This is significant because it has expanded the type of ligand that can be considered a target for aptamer development.

\section{DRUG/SMALL MOLECULE RNA APTAMER INTERACTIONS}

\section{Neomycin}

he antibiotics that target rRNA have been investigated further by the development of aptamers that bind them with high affinity and specificity. Neomycin B is an aminoglycoside antibiotic that inhibits a variety of RNA-mediated biological functions [71]. The structure-function relationship of Neomycin B and other aminoglycosides has been studied in detail with respect to the ribosome. Two binding sites have been identified, one on helix 44 of the small ribosomal unit and the other on helix 69 of the large ribosomal subunit. In the small ribosomal subunit, neomycin binds within a pocket formed by an A:A base pair and an unpaired A. These residues are responsible for increasing affinity to cognate
tRNA-mRNA pairings. With the antibiotic bound the ribosome is immobilized into a high affinity configuration that recognizes both cognate and noncognate tRNA-mRNA complexes thereby leading to miscoding [72]. In the large ribosomal subunit it binds within helix 69 with binding stabilized by contacts including a CAAUAC loop and G1906. This helix is swung away from an interface of subunit association by the ribosome recycling factor (RRF). Binding of the antibiotic restores interactions destabilized by the RRF and inhibits ribosome recycling [73]. The structure of Neomycin B in complex with HIV-1 DIS (previous mentioned) has since been crystallized. This binding interaction is similar to that involved in the small ribosomal unit [74 - 76]. These structures reveal that the mode of interaction between RNA and Neomycin B can vary. The binding of Neomycin B to its aptamer has been investigated to obtain a better understanding of aminoglycoside-RNA interactions, Figure 3 shows a few of the different structures of Neomycin B RNA binding pockets.

Neomycin B binds to the aptamer within a pocket consisting of three consecutive GU base pairs and a flap formed by an adenine base [77]. This pocket is different from the aforementioned binding sites. Further investigation of this interaction showed that hydrogen bonding interactions between aptamer and ligand are the major mechanism responsible for binding [79]. A more recent study used NMR techniques to show that protonation of Neomycin B accompanies binding its cognate aptamer, demonstrating the ability of RNA to influence its ligand [80]. The thermodynamic differences in binding of these complexes and other RNA complexes will be discussed in the following section. Other antimicrobial agents have been used as targets for development of aptamers. These include tetracycline, tobramycin and streptomycin. Characterization of these complexes has illuminated different aspects of RNA small molecule interactions and most of these aptamers have also been used to develop biosensors for medical applications [80]. For example the tobramycin aptamer has been incorporated as part of an aptasensor that can detect tobramycin and other aminoglycosides in human serum [82]. 

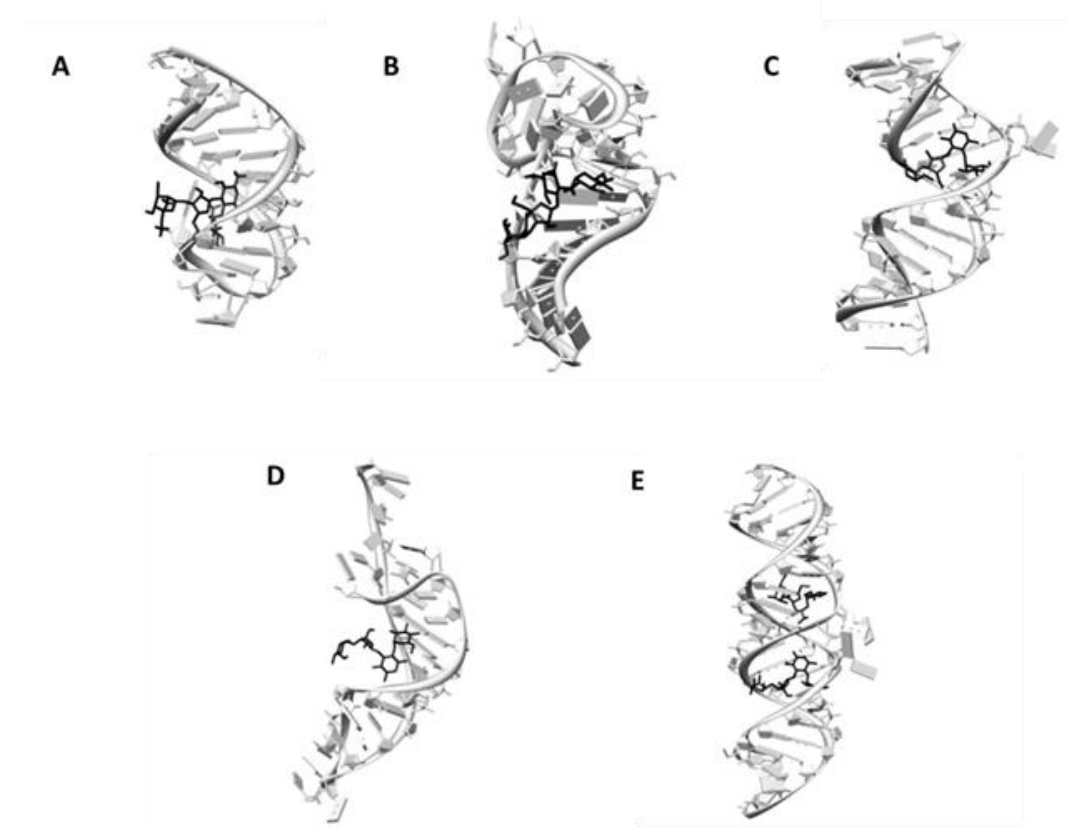

Figure 3. Neomycin B bound to RNA. A) Neomycin B aptamer, PDB ID 1NEM [77], B) HIV TAR, PDB ID 1QD3 [78], C) 30S ribosome Neomycin binding site, PDB ID 2QAN [73], D) 50S ribosome Neomycin B binding site, PDB ID 2QAO [74], E) HIV DIS complex, PDB ID 3C7R [75].

Neomycin B is coloured black. RNA is coloured grey. This figure shows the variety of different RNA sequences that can interact with Neomycin B. Figure was generated using UCSF Chimera [52].

\section{Tetracycline}

Tetracycline, tobramycin and streptomycin are antibiotics that like neomycin, target the bacterial ribosome. The tetracycline aptamer boasts a more complicated aptamer structure than usually obtained by SELEX against a small molecule [83]. The tetracycline aptamer consists of three helices, creating a binding site out of tertiary contacts between the helices. ITC studies of the tetracycline riboswitch revealed a two-step binding mechanism driven by favourable enthalpy. Tetracycline's interaction with the $30 \mathrm{~S}$ ribosomal subunit is stabilized by hydrogen bonding interactions as opposed to the aptamer which has stacking interactions with two rings of tetracycline [84].

\section{Tobramycin and Streptomycin}

The structures of two aptamers selected for tobramycin have been solved $[85,86]$. Both aptamer tobramycin complexes revealed that the antibiotic binds within a deep groove and has multiple hydrogen bonding contacts with the RNA. While both aptamers share the binding motif, one uses a base bulge to widen RNA major groove while the other has three mismatch pairs. Since both aptamers have comparable binding affinities this example reveals that changes to the binding site can be diverse. The streptomycin aptamer has also been studied by the same group that investigated the structure of tobramycin and neomycin aptamers [87]. This aptamer consists of $\mathrm{S}$ turns that create a cavity to encapsulate streptomycin.

\section{Purine}

Naturally occurring aptamers consist mainly of riboswitches, these sequences affect the secondary structure upon binding its ligand to allow for transcription of the following sequence. Similarity between an artificially selected aptamer and naturally occurring RNA can be seen in purine binding RNAs. The structure of the purine riboswitch has been obtained and reveals that the ligand is encapsulated by the RNA [88]. Kinetic studies of this binding interaction suggest that the ligand first engages in Watson-Crick base pairing with Y74 followed by a loop closure that traps the ligand in the binding pocket and subsequent formation of hydrogen bonds between ligand and RNA. Furthermore mutation studies of the purine riboswitch reveal the ability of RNA to form a bound-like structure through ligand mimicking. The term ligand mimicking is used to describe a receptor mimicking the presence of a ligand with a residue that has characteristics of the 
ligand. The mutant purine riboswitch is inactive, with one of its nucleotides (G39) occupying the active site [89]. While the structure is not yet available other biochemical methods suggest that an artificially selected adenine aptamer has a similar dependence on hydrogen bonding versus stacking interactions [90].

The guanine aptamer has a consensus sequence similar to tobacco ring spot virus satellite RNA hairpin ribozyme [91]. The part of purine riboswitch sequence that matches closest to the guanine aptamer is involved in binding (Figure 4). The purine riboswitch family has been reviewed in more detail $[92,93]$.This family includes the purine riboswitch discussed above as well as preQ [93], cyclic-dGMP [95] and tetrahydrofolate [96] binding riboswitches.
A)

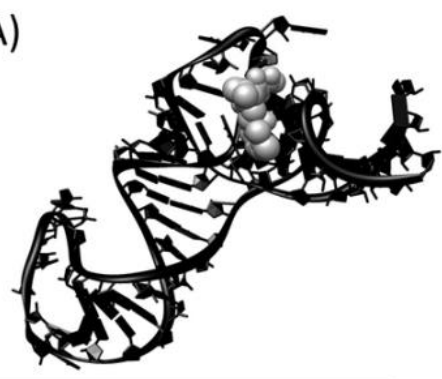

B)

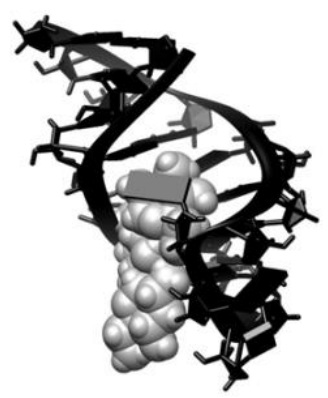

D)

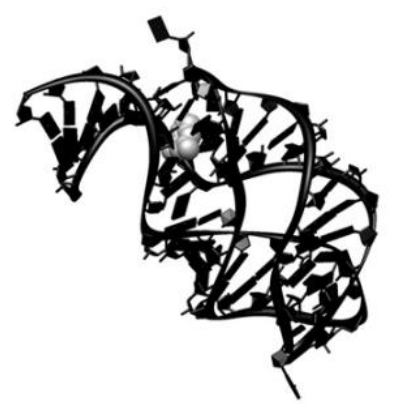

E)

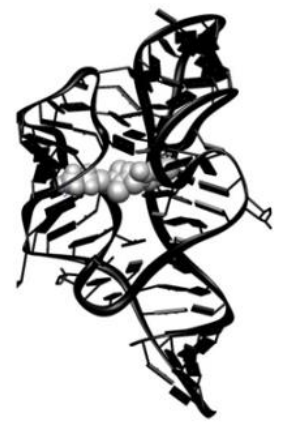

C)

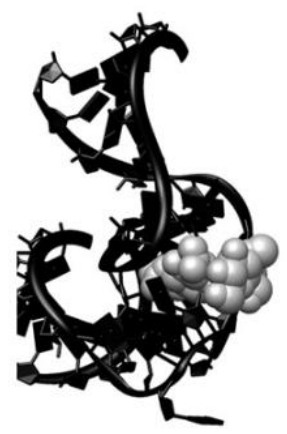

F)

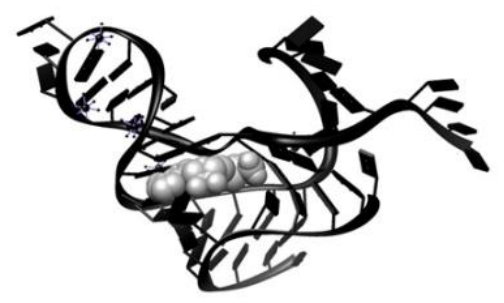

Figure 4.

RNA aptamers (black) complexed with small molecules (grey). A) Tetracycline aptamer complex, PDB ID 3EGZ [84], showing three helix wrapping around target. B) Tobramycin aptamers complex, PDB ID 2TOB [85], showing target binding within deep groove. C) Streptomycin aptamers complex, PDB ID 1NTB [87], showing S turn wrapping target. D) Purine aptamer complex, PDB ID 2B57 [88], showing target buried within aptamer. E) TPP aptamer complex, PDB ID 3K0J [99], showing target interacting with two stems. F) AdoMet aptamer complex PDB ID 3NPQ [102], showing the target interaction with RNA. Figure was generated using UCSF Chimera [52].

\section{Thiamine pyrophosphate}

Thiamine pyrophosphate (TPP) is a cofactor that regulates expression of proteins that are involved in the biosynthesis and transport of thiamine [97, 98]. The regulation occurs via the TPP riboswitch. TPP binds to the riboswitch between two parallel stems [99]. Investigation into the folding on this riboswitch has shown a two-step binding process involving first ligand independent secondary structure formation followed by ligand dependent tertiary structure formation [100].

\section{S-Adenosyl methionine}

The S-Adenosyl methionine (AdoMet) riboswitch is important in the regulation of amino acid biosynthesis [101]. The structural study of the AdoMet bound aptamer revealed that the interaction between RNA and AdoMet primarily involves the 
adenosine of AdoMet. Investigation of the interaction of other metabolites with the AdoMet riboswitch has suggested possible regulatory roles [102]. The AdoMet riboswitch is a potential target for antimicrobials due to its regulatory role in bacteria [103].

\section{THERMODYNAMICS OF RNA-LIGAND INTERACTIONS}

The binding of two molecules is generally discussed in terms of the free energy change $(\Delta \mathrm{G})$, the enthalpy change $(\Delta \mathrm{H})$, the entropy change $(\Delta \mathrm{S})$ and dissociation constant $\left(\mathrm{K}_{\mathrm{d}}\right)$. The thermodynamic parameters involved in binding interactions are related to each other by the Gibbs Helmholz equation (Equation 1).

$$
\Delta \mathrm{G}=\Delta \mathrm{H}-\mathrm{T} \Delta \mathrm{S} \quad \text { (Equation 1) }
$$

$\Delta \mathrm{G}$ is related to the binding affinity by Equation 2, with $\mathrm{R}$ being the gas constant and $\mathrm{T}$ the absolute temperature.

$$
\Delta \mathrm{G}=\mathrm{RT} \ln \left(1 / \mathrm{K}_{\mathrm{d}}\right) \quad \text { (Equation 2) }
$$

It is apparent from these equations that binding is stronger, $K_{d}$ lower, the more negative the value of $\Delta G$ is. From Equation 1 it can be gleaned that a negative $\Delta \mathrm{H}$ will push the value of $\Delta \mathrm{G}$ to a larger negative value. Likewise, a positive value for $\Delta \mathrm{S}$ will push the value of $\Delta \mathrm{G}$ to a larger negative value. A negative value of $\Delta \mathrm{H}$ will be referred to as favourable $\Delta \mathrm{H}$ and is associated with the increase of interactions between ligand and receptor, while a positive value of $\Delta \mathrm{H}$ will be referred to as unfavourable $\Delta \mathrm{H}$ and is associated with reducing number of interactions [104]. A negative value of $\Delta \mathrm{S}$ will be referred to as unfavourable $\Delta \mathrm{S}$ and is associated with a decrease in randomness (e.g. restricting movement) while a positive value of $\Delta \mathrm{S}$ will be referred to as favourable $\Delta \mathrm{S}$ and is associated with an increase in randomness (e.g. release of water molecules) [104].

Table 1 shows a summary of thermodynamic data for binding of the above mentioned RNA targets. The general trend is that binding is driven by favourable $\Delta \mathrm{H}$ which is countered by unfavourable $\Delta \mathrm{S}$. The two outliers to this trend are the purine riboswitch and the DIS HIV kissing loop.

Table 1: Summary of RNA Binding Thermodynamic Data.

\begin{tabular}{|c|c|c|c|c|c|c|}
\hline Target & RNA & $\Delta \mathbf{H}(\mathbf{k c a l} / \mathbf{m o l})$ & $\Delta \mathbf{S}(\mathbf{k c a l} / \mathbf{m o l} / \mathbf{K})$ & $\Delta \mathbf{G}(\mathbf{k c a l} / \mathbf{m o l})$ & $\mathbf{K}_{\mathbf{d}}(\mathbf{n M})$ & References \\
\hline Neomycin B & Aptamer & -21.6 & $-4.40 \mathrm{E}-02$ & -8.49 & $6.90 \mathrm{E}+02$ & {$[78]$} \\
\hline Tetracycline & Aptamer & -22.9 & $-3.52 \mathrm{E}-02$ & -12.4 & $1.00 \mathrm{E}+00$ & {$[95]$} \\
\hline Purine & Riboswitch & -40.3 & $-9.76 \mathrm{E}-02$ & -10.7 & $1.70 \mathrm{E}+01$ & {$[87]$} \\
\hline AdoMet & Riboswitch & -24.0 & $-4.62 \mathrm{E}-02$ & -10.2 & $3.20 \mathrm{E}+01$ & {$[92]$} \\
\hline Tyrosinamide & DNA Aptamer & -23.7 & $-5.39 \mathrm{E}-02$ & -7.64 & $2.44 \mathrm{E}+03$ & {$[96]$} \\
\hline Malachite green & Aptamer & -25.9 & $-5.69 \mathrm{E}-02$ & -8.79 & $2.80 \mathrm{E}+02$ & {$[97]$} \\
\hline Neomycin B & DIS kissing-loop & -9.4 & $2.70 \mathrm{E}-03$ & -10.2 & $3.40 \mathrm{E}+01$ & {$[73]$} \\
\hline Neomycin B & Ribosomal A site & -16.2 & $-2.79 \mathrm{E}-02$ & -7.90 & $1.55 \mathrm{E}+03$ & {$[98]$} \\
\hline TPP & Riboswitch & -58.1 & $-1.62 \mathrm{E}-02$ & -7.70 & $2.00 \mathrm{E}+02$ & {$[100]$} \\
\hline
\end{tabular}

The purine riboswitch has a higher amount of favourable enthalpy change while DIS HIV kissing loop has a lower $\Delta \mathrm{H}$. It is interesting to note that in both cases the variation of favourable $\Delta H$ is compensated by the inverse adjustment in unfavourable $\Delta$ S. The DIS HIV binding has a $20 \%$ greater amount of $\Delta \mathrm{G}$ from charge related interactions than the small ribosomal binding site [74]. While the purine riboswitch has a significant amount of hydrogen bonding [88], this could explain the $\Delta \mathrm{H}$ differences. These two examples suggest that artificially selected aptamer binding follows a different trend compared to the naturally occurring RNA small molecule interactions. However examining the AdoMet riboswitch the thermodynamic parameters are almost identical to the aptamers. This suggests that there is still too small a set of data to make generalizations about the thermodynamic trends. The similarity in energetics of binding is eclipsed by the specificity of each binding pocket created by differences in sequence and geometry of the binding pocket (Table 2). An interesting trend is observed in the investigation of small molecule binding aptamers, binding involves 
two stages $[84,105,100]$. The first stage is an interaction independent of the target and the second stage is target dependent. The knowledge of these thermodynamic distinguishable steps should provide for clues to improve target recognition.

Table 2: RNA Sequences For Various Targets With Structural Features Identified To Showcase The Difference In Sequence And Structure.

\begin{tabular}{|c|c|c|c|c|}
\hline Target & Sequence & $\begin{array}{l}\text { Notable Structural } \\
\text { Features }\end{array}$ & PDB & Ref\# \\
\hline Neomycin B & GGACUGGGCGAGAAGUUUAGUCC & $\begin{array}{l}\text { three consecutive GU } \\
\text { base pairs }\end{array}$ & 1NEM & [77] \\
\hline Tetracycline & $\begin{array}{l}\text { GGGCCUAAAACAUACCAGAGAUCGCCACCCGCGCUUUA } \\
\text { AUCUGGAGAGGUGAAGAAUACGACCACCUAGGCUC }\end{array}$ & three helices & $3 E G Z$ & [84] \\
\hline Tobramycin & GGGACUUGGUUUAGGUAAUGAGUCCC & $\begin{array}{l}\text { UG,GU,GA,UU base } \\
\text { pairs }\end{array}$ & $2 \mathrm{TOB}$ & [85] \\
\hline Streptomycin & $\begin{array}{l}\text { GGAUCGCAUUUGGACUUCUGCC/CGGCACCACGGUCGG } \\
\text { AUC }\end{array}$ & S turns & 1NTB & [87] \\
\hline Purine & $\begin{array}{l}\text { GCGAGUAUAACCUCAAUAAUAUGGUUUGAGGGUGUCUA } \\
\text { CCAGGAACCGUAAAAUCCUGACUACUCGC }\end{array}$ & $\begin{array}{l}\text { Encapsulating ligand, } \\
\text { base pairing with Y74 }\end{array}$ & 2B57 & [88] \\
\hline Guanine & GGCACGUGUAUUACCCUAGUGGUCGACGUGCC & $\begin{array}{l}\text { structure not } \\
\text { available }\end{array}$ & $\mathrm{n} / \mathrm{a}$ & [89] \\
\hline AdoMet & $\begin{array}{l}\text { GGACGAGGAGCGCUGCAAGCGAGAGCCCGAAGCUCGU } \\
\text { CCGUUCAAACGGCGCUCA }\end{array}$ & Psuedoknot & $3 N P Q$ & [102] \\
\hline$T P P$ & $\begin{array}{l}\text { GCGACTCGGGGTGCCCTTCTGCGTGAAGGCTGAGAAATA } \\
\text { CCCGTATCACCTGATCTGGATAATGCCAGCGTAGGGAAG } \\
\text { TCGC }\end{array}$ & Two parallel stems & $2 \mathrm{HOJ}$ & [99] \\
\hline HIV Rev & GGUGUCUUGGAGUGCUGAUCGGACACC & $\begin{array}{l}\text { UAU triple, hydrogen } \\
\text { bonding with Arg } 35 \\
\text { and Arg } 39, \\
\text { elongated form }\end{array}$ & 484D & [42] \\
\hline HIV Rev & GGCUGGACUCGUACUUCGGUACUGGAGAAACAGCC & $\begin{array}{l}\text { UAU triple, stacking } \\
\text { of Trp45, helical form }\end{array}$ & $1 U L L$ & [46] \\
\hline HIV TAR & GGCUGGUCCCAGACGACC & kissing complex & 2RN1 & {$[50]$} \\
\hline HIV DIS & CUUGCUGAAGUGCACACGCAAG & kissing complex & 3C7R & [75] \\
\hline HIV Tat & GGGAGCUUGAUCCCGGAAACGGUCGAUCGCUCCC & $\begin{array}{l}\text { two adjacent UAU } \\
\text { triples }\end{array}$ & $1 \mathrm{NBK}$ & [41] \\
\hline $\begin{array}{l}\text { MS2 coat } \\
\text { protein }\end{array}$ & CCGGAGGUCACCACGGG & $\begin{array}{l}\text { A10 makes three } \\
\text { hydrogen bonds with } \\
\text { target }\end{array}$ & $1 \mathrm{U} 1 \mathrm{Y}$ & [56] \\
\hline $\begin{array}{l}\text { RNA } \\
\text { polymerase II }\end{array}$ & ACAGCACUGAUUGCGGUCGAGGUAGCUUGAUGG & A-form helix & 2B63 & [60] \\
\hline Prion & GGAGGAGGAGGA & GGGG tetraplane & 2RQJ & [66] \\
\hline Human IgG & GGAGGUGCUCCGAAAGGAACUCCA & $\begin{array}{l}\text { G7 stacking with } \\
\text { Tyr373 }\end{array}$ & 3AGV & [70] \\
\hline$N F-\kappa b$ factor & GAUACUUGAAACUGUAAGGUUGGCGUAUC & $\begin{array}{l}\text { resembles B-form } \\
\text { DNA }\end{array}$ & $100 \mathrm{~A}$ & [61] \\
\hline $\begin{array}{l}\text { Mammalian } \\
\text { factor } 4 A\end{array}$ & $\begin{array}{l}\text { GGAGAUCGCACUCCACAUGUGAGUGAGGCCGAAACAUA } \\
\text { GAUUCGAGAGGAGGCUCACA }\end{array}$ & AUCGCA loop & $\mathrm{n} / \mathrm{a}$ & [64] \\
\hline
\end{tabular}

\section{CONCLUSIONS}

A common trend seen with the aptamers selected for larger biomolecules is that they mimic the type of interactions that already exist in organisms. This is seen clearly in the aptamer for TAR HIV RNA, which forms a kissing complex similar to that seen in HIV DIS [50, 51]. This phenomenon is implied by the work with RNA polymerase II aptamer and
B2RNA competitive binding to RNA polymerase II [59].

In the case of aptamers for antibiotics the naturally occurring RNA that binds to the same targets has clear differences in binding pockets. This is a reflection of the evolution of RNA, since the naturally occurring RNA did not have a selection pressure driven purely by affinity to target, but rather by their function within the system (cell/virus). As 
seen in the case of tobramycin with two aptamers that use different means to widen binding pocket $[85,86]$ and multiple ATP aptamers [106] it is possible to have variations of sequences that have strong binding affinity and nature has had multiple variations to explore other functions.

The closer relatives to artificially selected aptamers, riboswitches, share similarity, at least in the case of adenine. Another example of similarity in sequence between artificially selected aptamer and naturally occurring RNA is that of the ATP aptamer binding motif which was found in a bacterial virus [107]. The aptamers selected for small molecules do provide a window into the capacity for function inherent to RNA, and the roles it could have played in a prebiotic world.

The number of aptamers is increasing as methods to select them become more routine and even include in silico techniques [108]. 2',4'-Locked RNA aptamers are aptamers which include a 2'-O, 4'-C methylene link, which confers a C3' endo conformation. This change results in an entropic constraint that leads to increased affinity for their target [109]. This along with other developments in degradation resistant nucleotides [110] promises many applications for aptamers to come.

RNA binding usually involves adaptive interactions. This has been seen for binding to peptides and small molecules [42, $111-113]$. This behavior makes it important to probe the conformational mobility and thermodynamics of binding so that the aptamer target molecule interaction can be fully characterized. This line of investigation can be supplemented by sitedirected modification of the aptamer to change the spatial configuration or the energy of the binding interaction. For example the binding affinity of tRNA gln to glutaminyl-tRNA synthetase was improved by studying the related aptamer. The improvements did not involve the RNA protein contacts but instead were driven by tertiary structure stabilization of the RNA [114]. Another important reason for the study of structure and thermodynamics of RNA-ligand interactions is to understand the nature of RNAinduced modifications of the ligand itself. A good example of such behaviour is seen in the conformational changes induced in malachite green molecules binding to their cognate aptamer, and these changes are significant enough to change the optical properties of the dye molecule [115]. This type of binding interaction could expand modalities of drug interactions, such as aptamer-assisted pro-drug delivery.

Understanding the nature of the interactions between target and drug molecule has improved the rational design of protein targeting molecules [38]. The structure-function paradigm is being applied to rational design of biologically active therapeutic RNA. This effort is assisted by the use of aptamer models to understand nature of RNA-molecule interactions.

\section{REFERENCES}

[1] Bartel, D. P., MicroRNAs: Genomics, biogenesis, mechanism, and function. Cell 2007, 131 (4), 11-29.

[2] Beringer, M., Modulating the activity of the peptidyl transferase center of the ribosome. RNA 2008, 14 (5), 795-801.

[3] Brenner, S.; Meselson, M.; Jacob, F., Unstable intermediate carrying information from genes to ribosomes for protein synthesis. Nature 1961, 190 (477), 576-581.

[4] Crick, F. H., On protein synthesis. Symposia of the Society for Experimental Biology 1958, 12, 138163.

[5] Crick, F. H.; Brenner, S.; Watstobi.Rj; Barnett, L., General nature of genetic code for proteins. Nature,

1961, 192 (480), 1227-1232.

[6] Guerrier-Takada, C.; Gardiner, K.; Marsh, T.; Pace, N.; Altman, S., The RNA moiety of ribonuclease $\mathrm{P}$ is the catalytic subunit of the enzyme. Cell 1983, 35 (3 Pt 2), 849-857.

[7] Cech, T. R.; Zaug, A. J.; Grabowski, P. J., In vitro splicing of the ribosomal RNA precursor of Tetrahymena: involvement of a guanosine nucleotide in the excision of the intervening sequence. Cell 1981, 27 (3 Pt 2), 487-496.

[8] Gilbert, W., Origin of life - The RNA World. Nature 1986, 319 (6055), 618-618.

[9] Kay, J., Role of ribosomal RNA (rRNA) synthesis in effects of phytohaemagglutinin (PHA) on lymphocytes. Fed. Proc., Fed. Amer. Soc. Exp. Biol., 1968, Vol. 27, pp 717-720.

[10] Morris, D.; Demoss, J., Role of aminoacyltransfer ribonucleic acid in regulation of ribonucleic acid synthesis in Escherichia Coli. J. Bacteriol. 1965, 90 (6), 1624-1626.

[11] Tso, P. O. P., Ribosomes - Ribonucleoprotein Particles. Annu. Rev. Plant Physiol. Plant Mol. Biol., 1962, 13, 45-50.

[12] Salas, M.; Hille, M. B.; Last, J. A.; Wahba, A. J.; Ochoa, S., Translation of genetic message .2. Effect of initiation factors on binding of formyl-methionyltRNA to ribosomes. Proc. Natl. Acad. Sci. U.S.A., 1967, 57 (2), 387-394.

[13] Bock, R. M.; Soll, D.; Cherayil, J. D., Mechanism of codon recognition by tRNA. Indian $J$. Biochem., 1967, 4 (2), 25-30.

[14]Harvey Lodish, A. B., S Lawrence Zipursky, Paul Matsudaira, David Baltimore, and James 
Darnell., Molecular Cell Biology. 4th ed.; W. H. Freeman and Company, New York, 2000. [15] Nissen, P.; Hansen, J.; Ban, N.; Moore, P. B.; Steitz, T. A., The structural basis of ribosome activity in peptide bond synthesis. Science, 2000, 289 (5481), 920-930.

[16] Cech, T. R., Crawling Out of the RNA World. Cell, 2009, 136 (4), 599-602.

[17] Hamilton, A.; Baulcombe, D., A species of small antisense RNA in posttranscriptional gene silencing in plants. Science, 1999, 286 (5441), 950-952.

[18] Ganot, P.; Caizergues-Ferrer, M.; Kiss, T., The family of box ACA small nucleolar RNAs is defined by an evolutionarily conserved secondary structure and ubiquitous sequence elements essential for RNA accumulation. Genes Dev. 1997, 11 (7), 941-956. [19] Grivna, S.; Beyret, E.; Wang, Z.; Lin, H., A novel class of small RNAs in mouse spermatogenic cells. Genes Dev., 2006, 20 (13), 1709-1714.

[20] Ben Amor, B.; Wirth, S.; Merchan, F.; Laporte, P.; d'Aubenton-Carafa, Y.; Hirsch, J.; Maizel, A.; Mallory, A.; Lucas, A.; Deragon, J. M.; Vaucheret, H.; Thermes, C.; Crespi, M., Novel long non-protein coding RNAs involved in Arabidopsis differentiation and stress responses. Genome Res., 2009, 19 (1), 5769.

[21] Winkler, W. C.; Cohen-Chalamish, S.; Breaker, R. R., An mRNA structure that controls gene expression by binding FMN. Proc. Natl. Acad. Sci. U.S.A. 2002, 99 (25), 15908-15913.

[22] Dinger, M.; Mercer, T.; Mattick, J., RNAs as extracellular signaling molecules. J. Mol. Endocrinol., 2008, 40 (3-4), 151-159.

[23] Hannon, G. J.; Rossi, J. J., Unlocking the potential of the human genome with RNA interference. Nature 2004, 431 (7006), 371-378.

[24] Carthew, R. W.; Sontheimer, E. J., Origins and Mechanisms of miRNAs and siRNAs. Cell 2009, 136 (4), 642-655.

[25] Balakin, A. G.; Smith, L.; Fournier, M. J., The RNA World of the Nucleolus - Two Major Families of Small RNAs Defined By Different Box Elements With Related Functions. Cell 1996, 86 (5), 823-834. [26] Wahid, F.; Khan, T.; Hwang, K. H.; Kim, Y. Y., Piwi-interacting RNAs (piRNAs) in animals: The story so far. Afr. J. Biotechnol. 2009, 8 (17), 40024006.

[27] Winkler, W.; Nahvi, A.; Breaker, R. R., Thiamine derivatives bind messenger RNAs directly to regulate bacterial gene expression. Nature 2002, 419 (6910), 952-956.
[28] Ellington, A. D.; Szostak, J. W., In vitro selection of RNA molecules that bind specific ligands. Nature 1990, 346, 818-822.

[29] Tuerk, C.; Gold, L., Systematic evolution of ligands by exponential enrichment: RNA ligands to bacteriophage T4 DNA polymerase. Science 1990, 249, 505-510.

[30] Bouchard, P. R.; Hutabarat, R. M.; Thompson, K. M., Discovery and development of therapeutic aptamers. Annu. Rev. Pharmacol. Toxicol. 2010, 50, 237-257.

[31] Dyke, C. K.; Steinhubl, S. R.; Kleiman, N. S.; Cannon, R. O.; Aberle, L. G.; Lin, M.; Myles, S. K.; Melloni, C.; Harrington, R. A.; Alexander, J. H.; Becker, R. C.; Rusconi, C. P., First-in-human experience of an antidote-controlled anticoagulant using RNA aptamer technology: a phase 1a pharmacodynamic evaluation of a drug-antidote pair for the controlled regulation of factor IXa activity. Circulation 2006, 114 (23),2490-2497.

[32] Ng, E. W.; Adamis, A. P., Anti-VEGF aptamer (pegaptanib) therapy for ocular vascular diseases. Ann. N. Y. Acad. Sci. 2006, 1082, 151-171.

[33] Bates, P. J.; Laber, D. A.; Miller, D. M.; Thomas, S. D.; Trent, J. O., Discovery and development of the G-rich oligonucleotide AS1411 as a novel treatment for cancer. Exp.Mol. Pathol. 2009, 86, 151-164. [34] Deissler, H. L; Lang, G. E., Effect of VEGF(165) and the VEGF Aptamer Pegaptanib (Macugen (R)) on the Protein Composition of Tight Junctions in Microvascular Endothelial Cells of the Retina. Klin. Monbl. Augenheilkd. 2008, 225, 863-867.

[35] Veronese, F. M.; Mero, A., The impact of PEGylation on biological therapies. Biodrugs 2008, 22, 315-329.

[36] Burnett, J. C.; Rossi, J. J.; Tiemann, K., Current progress of siRNA/shRNA therapeutics in clinical trials. Biotechnol. J. 2011, 6 (9), 1130-1146.

[37] Schubert, S.; Kurreck, J., Ribozyme- and deoxyribozyme-strategies for medical applications. Curr. Drug Targets 2004, 5 (8), 667-681. [38] Noble, M.; Endicott, J.; Johnson, L., Protein kinase inhibitors: Insights into drug design from structure. Science 2004, 303 (5665), 1800-1805. [39] Lee, J. H.; Canny, M. D.; De Erkenze, A.; Krilleke, D.; Ng, Y. S.; Shima, D. T.; Pardi, A.; Jucker, F. A therapeutic aptamer inhibits angiogenesis by specifically targeting the heparin binding domain of VEGF 165. Proc. Natl. Acad. Sci.USA 2005, 102, (52), 18902-18907.

[40] Lebars, I.; Legrand, P.; Aime, A.; Pinaud, N.; Fribourg, S.; Di Primo, C., Exploring TAR-RNA aptamer loop-loop interaction by $\mathrm{X}$-ray 
crystallography, UV spectroscopy and surface plasmon resonance. Nucleic Acids Res., 2008, 36 (22), 7146-7156.

[41] Matsugami, A.; Kobayashi, S.; Ouhashi, K.; Uesugi, S.; Yamamoto, R.; Taira, K.; Nishikawa, S.; Kumar, P.; Katahira, M., Structural basis of the highly efficient trapping of the HIV Tat protein by an RNA aptamer. Structure 2003, 11 (5), 533-545.

[42] Ye, X.; Gorin, A.; Frederick, R.; Hu, W.; Majumdar, A.; Xu, W.; McLendon, G.; Ellington, A.; Patel, D., RNA architecture dictates the conformations of a bound peptide. Chem. Biol., 1999, $6(9), 657-669$.

[43] Zapp, M. L.; Hope, T. J.; Parslow, T. G.; Green, M. R., Oligomerization and RNA binding domains of the type 1 human immunodefieciency virus Rev protein: A dual function for an arginine-rich binding motif. Proc. Natl. Acad. Sci. USA, 1991, 88, 77347738 .

[44] Tiley, L. S.; Malim, M. H.; Tewary, H. K.; Stockley, P. G.; Cullen, B. R., Identification of a high-affinity RNA-binding site for the human immunodeficiency virus type 1 Rev protein. Proc. Natl. Acad. Sci. USA, 1992, 89, 758-762.

[45] Heaphy, S.; Finch, J. T.; Gait, M. J.; Karn, J.; Singh, M., Human immunodeficiency virus type 1 regulator of virion expression, rev, forms nucleoprotein filaments after binding to a purine-rich "bubble" located within the rev-responsive region of viral mRNAs. Proc. Natl. Acad. Sci. USA, 1991, 88, 7366-7370.

[46] Ye, X.; Gorin, A.; Ellington, A. D.; Patel, D. J., Deep penetration of an alpha-helix into a widened RNA major groove in the hiv-1 rev peptide-rna aptamer complex. Nat. Struct. Biol. 1996, 3, 1026. [47] Frankel, A. D., Activation of HIV transcription by Tat. Curr. Opin. Genet. Dev., 1992, 2 (2), 293-298. [48] Tao, J. S.; Frankel, A. D., Specific binding of arginine to TAR RNA. Proc. Natl. Acad. Sci. USA, 1992, 89 (7), 2723-2726.

[49] Yamamoto, R.; Katahira, M.; Nishikawa, S.; Baba, T.; Taira, K.; Kumar, P. K., A novel RNA motif that binds efficiently and specifically to the Ttat protein of HIV and inhibits the trans-activation by Tat of transcription in vitro and in vivo. Genes Cells, England, 2000; Vol. 5, pp 371-388.

[50] Van Melckebeke, H.; Devany, M.; Di Primo, C.; Beaurain, F.; Toulme, J. J.; Bryce, D. L.; Boisbouvier, J., Liquid-crystal NMR structure of HIV TAR RNA bound to its SELEX RNA aptamer reveals the origins of the high stability of the complex. Proc. Natl. Acad. Sci. USA, 2008, 105 (27), 9210-9215.
[51] Paillart, J. C.; Shehu-Xhilaga, M.; Marquet, R.; Mak, J., Dimerization of retroviral RNA genomes: an inseparable pair. Nat. Rev. Microbiol., 2004, 2 (6), 461-472.

[52] Pettersen, E. F.; Goddard, T. D.; Huang, C. C.; Couch, G. S.; Greenblatt, D. M.; Meng, E. C.; Ferrin, T. E., UCSF chimera - A visualization system for exploratory research and analysis. J Comput. Chem., 2004, 25 (13), 1605-1612.

[53] Stonehouse, N. J.; Scott, D. J.; Fonseca, S.; Murray, J.; Adams, C.; Clarke, A. R.; Valegard, K.; Golmohammadi, R.; van den Worm, S.; Liljas, L.; Stockley, P. G., Molecular interactions in the RNA bacteriophage MS2. Biochem. Soc. Trans., 1996, 24 (3), $412 \mathrm{~S}$.

[54] Valegard, K.; Murray, J. B.; Stockley, P. G.; Stonehouse, N. J.; Liljas, L., Crystal structure of an RNA bacteriophage coat protein-operator complex. Nature 1994, 371 (6498), 623-626.

[55] Grahn, E.; Stonehouse, N. J.; Murray, J. B.; van den Worm, S.; Valegard, K.; Fridborg, K.; Stockley, P. G.; Liljas, L., Crystallographic studies of RNA hairpins in complexes with recombinant MS2 capsids: implications for binding requirements. $R N A$, 1999, 5 (1), 131-138.

[56] Horn, W.; Convery, M.; Stonehouse, N.; Adams, C.; Liljas, L.; Phillips, S.; Stockley, P., The crystal structure of a high affinity RNA stem-loop complexed with the bacteriophage MS2 capsid: Further challenges in the modeling of ligand-RNA interactions. RNA., 2004, 10 (11), 1776-1782.

[57] Espinoza, C. A.; Goodrich, J. A.; Kugel, J. F., Characterization of the structure, function, and mechanism of B2 RNA, an ncRNA repressor of RNA polymerase II transcription. $R N A, \mathbf{2 0 0 7}, 13$, pp 583596.

[58] Trotochaud, A. E.; Wassarman, K. M., A highly conserved 6S RNA structure is required for regulation of transcription. Nat. Struct. Mol. Biol., 2005, 12, pp 313-319.

[59] Espinoza, C.; Allen, T.; Hieb, A.; Kugel, J.; Goodrich, J., B2 RNA binds directly to RNA polymerase II to repress transcript synthesis. Nature Struct. Mol. Biol., 2004, 11 (9), 822-829.

[60] Kettenberger, H.; Eisenfuhr, A.; Brueckner, F.; Theis, M.; Famulok, M.; Cramer, P., Structure of an RNA polymerase II-RNA inhibitor complex elucidates transcription regulation by noncoding RNAs. Nature Struct. Mol. Biol., 2006, 13 (1), 44-48. [61] Huang, D. B.; Vu, D.; Cassiday, L. A.; Zimmerman, J. M.; Maher, L. J.; Ghosh, G., Crystal structure of NF-kappa B (p50)(2) complexed to a 
high-affinity RNA aptamer. Proc. Natl. Acad. Sci. USA, 2003, 100 (16), 9268-9273.

[62] Darnell, J. E., Jr., Transcription factors as targets for cancer therapy. Nat. Rev. Cancer, 2002, 2, pp 740-749.

[63] Reiter, N.; Maher, L.; Butcher, S., DNA mimicry by a high-affinity anti-NF-kappa B RNA aptamer. Nucleic Acids Res., 2008, 36 (4), 1227-1236. [64] Sakamoto, T.; Oguro, A.; Kawai, G.; Ohtsu, T.; Nakamura, Y., NMR structures of double loops of an RNA aptamer against mammalian initiation factor 4A. Nucleic Acids Res., 2005, 33 (2), 745-754.

[65] Huang, Z.; Gabriel, J. M.; Baldwin, M. A.; Fletterick, R. J.; Prusiner, S. B.; Cohen, F. E., Proposed three-dimensional structure for the cellular prion protein. Proc. Natl. Acad. Sci. USA 1994, 91 (15), 7139-7143.

[66] Mashima, T.; Matsugami, A.; Nishikawa, F.; Nishikawa, S.; Katahira, M., Unique quadruplex structure and interaction of an RNA aptamer against bovine prion protein. Nucleic Acids Res. 2009, 37 (18), 6249-6258.

[67] Lauren, J.; Gimbel, D. A.; Nygaard, H. B.; Gilbert, J. W.; Strittmatter, S. M., Cellular prion protein mediates impairment of synaptic plasticity by amyloid-beta oligomers. Nature 2009, 457 (7233), 1128-1132.

[68] Proske, D.; Gilch, S.; Wopfner, F.; Schatzl, H. M.; Winnacker, E. L.; Famulok, M., Prion-proteinspecific aptamer reduces PrPSc formation.

Chembiochem 2002, 3 (8), 717-725.

[69] Litman, G. W.; Rast, J. P.; Shamblott, M. J.; Haire, R. N.; Hulst, M.; Roess, W.; Litman, R. T.; Hinds-Frey, K. R.; Zilch, A.; Amemiya, C. T., Phylogenetic diversification of immunoglobulin genes and the antibody repertoire. Mol. Biol. Evol., 1993, 10 (1), 60-72.

[70] Nomura, Y.; Sugiyama, S.; Sakamoto, T.; Miyakawa, S.; Adachi, H.; Takano, K.; Murakami, S.; Inoue, T.; Mori, Y.; Nakamura, Y.; Matsumura, H., Conformational plasticity of RNA for target recognition as revealed by the $2.15 \mathrm{~A}$ crystal structure of a human IgG-aptamer complex. In Nucleic Acids Res., 2010, 38, pp 7822-7829.

[71] Fourmy, D.; Recht, M. I.; Puglisi, J. D., Binding of neomycin-class aminoglycoside antibiotics to the A-site of 16 S rRNA. J. Mol. Biol. 1998, 277 (2), 347-362.

[72] Magnet, S.; Blanchard, J. S., Molecular insights into aminoglycoside action and resistance. Chemical Rev., 2005, 105 (2), 477-497.

[73] Borovinskaya, M.; Pai, R.; Zhang, W.; Schuwirth, B.; Holton, J.; Hirokawa, G.; Kaji, H.;
Kaji, A.; Cate, J., Structural basis for aminoglycoside inhibition of bacterial ribosome recycling. Nature Struct. Mol. Biol., 2007, 14 (8), 727-732.

[74] Bernacchi, S.; Freisz, S.; Maechling, C.; Spiess, B.; Marquet, R.; Dumas, P.; Ennifar, E., Aminoglycoside binding to the HIV-1 RNA dimerization initiation site: thermodynamics and effect on the kissing-loop to duplex conversion. Nucleic Acids Res., 2007, 35 (21), 7128-7139. [75] Freisz, S.; Lang, K.; Micura, R.; Dumas, P.; Ennifar, E., Binding of aminoglycoside antibiotics to the duplex form of the HIV-1 genomic RNA dimerization initiation site. Angew. Chem., 2008, 47 (22), 4110-4113.

[76] Ennifar, E.; Paillart, J.; Marquet, R.; Ehresmann, B.; Ehresmann, C.; Dumas, P.; Walter, P., HIV-1 RNA dimerization initiation site is structurally similar to the ribosomal A site and binds aminoglycoside antibiotics. J.Biol. Chem., 2003, 278 (4), 2723-2730.

[77] Jiang, L. C.; Majumdar, A.; Hu, W. D.; Jaishree, T. J.; Xu, W. K.; Patel, D. J., Saccharide-RNA recognition in a complex formed between neomycin B and an RNA aptamer. Structure 1999, 7 (7), 817827.

[78] Faber, C.; Sticht, H.; Schweimer, K.; Rosch, P., Structural rearrangements of HIV-1 Tat-responsive RNA upon binding of neomycin B. J. Biol. Chem., 2000, 275 (27), 20660-20666.

[79] Cowan, J. A.; Ohyama, T.; Wang, D. Q.; Natarajan, K., Recognition of a cognate RNA aptamer by neomycin B: quantitative evaluation of hydrogen bonding and electrostatic interactions. Nucleic Acids Res. 2000, 28 (15), 2935-2942. [80] Freire, F.; Cuesta, I.; Corzana, F.; Revuelta, J.; Gonzalez, C.; Hricovini, M.; Bastida, A.; JimenezBarbero, J.; Asensio, J. L., A simple NMR analysis of the protonation equilibrium that accompanies aminoglycoside recognition: Dramatic alterations in the neomycin-B protonation state upon binding to a 23-mer RNA aptamer. Chem. Comm., 2007, (2), 174-176.

[81] Liu, J.; Cao, Z.; Lu, Y., Functional nucleic acid sensors. Chem. Rev. 2009, 109 (5), 1948-1998. [82] Gonzalez-Fernandez, E.; de-los-Santos-Alvarez, N.; Lobo-Castanon, M. J.; Miranda-Ordieres, A. J.; Tunon-Blanco, P., Impedimetric aptasensor for tobramycin detection in human serum. Biosens. Bioelectron., 2011, 26, pp 2354-2360.

[83] Xiao, H.; Edwards, T.; Ferre-D'Amare, A., Structural Basis for Specific, High-Affinity Tetracycline Binding by an In Vitro Evolved 
Aptamer and Artificial Riboswitch. Chem. Biol., 2008, 15 (10), 1125-1137.

[84] Brodersen, D. E.; Clemons Jr, W. M.; Carter, A. P.; Morgan-Warren, R. J.; Wimberly, B. T.;

Ramakrishnan, V., The Structural Basis for the Action of the Antibiotics Tetracycline, Pactamycin, and Hygromycin B on the 30S Ribosomal Subunit. Cell, 2000, 103 (7), 1143-1154.

[85] Jiang, L. C.; Patel, D. J., Solution structure of the tobramycin-RNA aptamer complex. Nat. Struct. Biol. 1998, 5 (9), 769-774.

[86] Jiang, L. C.; Suri, A. K.; Fiala, R.; Patel, D. J., Saccharide-RNA Recognition in an Aminoglycoside Antibiotic-RNA Aptamer Complex. Chem. Biol. 1997, 4 (1), 35-50.

[87] Tereshko, V.; Skripkin, E.; Patel, D., Encapsulating streptomycin within a small 40-mer RNA. Chem. Biol., 2003, 10 (2), 175-187.

[88] Gilbert, S.; Stoddard, C.; Wise, S.; Batey, R., Thermodynamic and kinetic characterization of ligand binding to the purine riboswitch aptamer domain. J. Mol. Biol. 2006, 363 (2), 624-624.

[89] Delfosse, V.; Bouchard, P.; Bonneau, E.;

Dagenais, P.; Lemay, J.; Lafontaine, D.; Legault, P., Riboswitch structure: an internal residue mimicking the purine ligand. Nucleic Acids Res., 2010, 38 (6), 2057-2068.

[90] Meli, M.; Vergne, J.; Decout, J. L.; Maurel, M. C., Adenine-aptamer complexes: a bipartite RNA site that binds the adenine nucleic base. J. Biol. Chem., 2002, 277, pp 2104-2111.

[91] Kiga, D.; Futamura, Y.; Sakamoto, K.; Yokoyama, S., An RNA aptamer to the xanthine/guanine base with a distinctive mode of purine recognition. Nucleic Acids Res. 1998, 26 (7), 1755-1760.

[92] Batey, R. T., Structure and mechanism of purine-binding riboswitches. Q. Rev. Biophys. 2012, 45 (3), 345-381.

[93] Montange, R. K.; Batey, R. T., Riboswitches: Emerging themes in RNA structure and function.

Annu. Rev. Biophys. 2008, 37, 117-133.

[94] Roth, A.;Winkler, W. C.; Regulski, E. E.; Lee, B.W.; Lim, J.; Jona, L.; Barrick, J. E.; Ritwik, A.;

Kim, J. N.; Welz, R.; Iwata-Reuyl, D.; Breaker, R. R., A riboswitch selective for the queuosine precursor preQ1 contains an unusually small aptamer domain. Nat. Struct.Mol. Biol. 2007, 14 (4),308-317

[95] Smith, K. D.; Lipchock, S. V.; Ames, T. D.; Wang, J.; Breaker, R. R.; Strobel, S. A., Structural basis of ligand binding by a c-di-GMP riboswitch. Nat. Struct. Mol. Biol. 2009, 16, 1218-1223.
[96] Trausch, J. J.; Ceres, P.; Reyes, F.E.; Batey, R.T., The structure of a tetrahydrofolate-sensing riboswitch reveals two ligand binding sites in a single aptamer.

Structure 2011,19, 1413-1423.

[97] Winkler, W.; Nahvi, A.; Breaker, R. R., Thiamine derivatives bind messenger RNAs directly to regulate bacterial gene expression. Nature 2002, 419, 952-956.

[98] Sudarsan, N.; Cohen-Chalamish, S.; Nakamura, S.; Emilsson, G. M.; Breaker, R. R., Thiamine pyrophosphate riboswitches are targets for the antimicrobial compound pyrithiamine. Chem. Biol. 2005, 12,1325-1335.

[99] Kulshina, N.; Edwards, T. E.; Ferre-D'Amare, A. D., Thermodynamic analysis of ligand binding and ligand binding-induced tertiary structure formation by the thiamine pyrophosphate riboswitch. RNA $\mathbf{2 0 1 0}$, $16,186$.

[100] Furniss, S.; Grover, N., Thermodynamic examination of the pyrophosphate sensor helix in the thiamine pyrophosphate riboswitch. RNA 2011, 17, 710-717.

[101] Grundy, F. J.; Henkin, T. M., The S box regulon: a new global transcription termination control system for methionine and cysteine biosynthesis genes in Gram-positive bacteria. Mol. Microbiol., 1998, 30 (4), 737-749.

[102] Edwards, A.; Reyes, F.; Heroux, A.; Batey, R., Structural basis for recognition of S-

adenosylhomocysteine by riboswitches. $R N A, \mathbf{2 0 1 0}$, 16 (11), 2144-2155.

[103] Epshtein, V.; Mironov, A. S.; Nudler, E., The riboswitch-mediated control of sulfur metabolism in bacteria. Proc. Natl. Acad. Sci. USA, 2003, 100 (9), 5052-5056.

[104] Jelesarov, I.; Bosshard, H. R., Isothermal titration calorimetry and differential scanning calorimetry as complementary tools to investigate the energetics of biomolecular recognition. J. Mol.

Recognit., 1999, 12 (1), 3-18.

[105] Sokoloski, J. E.; Dombrowski, S. E.; Bevilacqua, P. C., Thermodynamics of ligand binding to a heterogeneous RNA population in the malachite green aptamer. Biochemistry 2012, 51, 565-572.

[106] Huang, Z.; Szostak, J. W., Evolution of aptamers with a new specificity and new secondary structures from an ATP aptamer. RNA 2003, 9 (12), 1456-1463.

[107] Shu, D.; Guo, P., A viral RNA that binds ATP and contains a motif similar to an ATP-binding aptamer from SELEX. J. Biol. Chem., 2003, 278 (9), 7119-7125. 
[108] Chushak, Y.; Stone, M. O., In silico selection of RNA aptamers. Nucleic Acids Res., 2009, 37, 8790.

[109] Schmidt, K. S.; Borkowski, S.; Kurreck, J.; Stephens, A. W.; Bald, R.; Hecht, M.; Friebe, M.; Dinkelborg, L.; Erdmann, V. A., Application of locked nucleic acids to improve aptamer in vivo stability and targeting function. Nucleic Acids Res., 2004, 32, pp 5757-5765.

[110] Minakawa, N.; Sanji, M.; Kato, Y.; Matsuda, A., Investigations toward the selection of fullymodified 4'-thioRNA aptamers: optimization of in vitro transcription steps in the presence of 4'thioNTPs. Bioorg. Med. Chem., 2008, 16, pp 94509456.

[111] Dieckmann, T., Adaptability and dynamics in RNA ligand interactions: The malachite green binding aptamer. Abstr. Papers Am. Chem. Soc., 2005, 229, U742-U742.

[112] Patel, D. J.; Suri, A. K.; Jiang, F.; Jiang, L.; Fan, P.; Kumar, R. A.; Nonin, S., Structure, Recognition and Adaptive Binding in RNA Aptamer Complexes. J. Mol. Biol. 1997, 272, 645-664.

[113] Flinders, J.; DeFina, S. C.; Brackett, D. M.; Baugh, C.; Wilson, C.; Dieckmann, T., Recognition of planar and nonplanar ligands in the malachite green-RNA aptamer complex. Chembiochem 2004, 5 (1), 62-72.

[114] Lee, D.; McClain, W. H., Aptamer redesigned tRNA is nonfunctional and degraded in cells. RNA, 2004, 10 (1), 7-11.

[115] Nguyen, D. H.; Dieckmann, T.; Colvin, M. E.; Fink, W. H., Dynamics studies of a malachite GreenRNA complex revealing the origin of the red-shift and energetic contributions of stacking interactions. $J$. Physical Chem. B, 2004, 108 (4), 1279-1286. 